\title{
REFLEXÕES CRÍTICO-ONTOLÓGICAS SOBRE INDIVÍDUO E EDUCAÇÃO NA PERSPECTIVA DA EMANCIPAÇÃO HUMANA
}

\author{
REFLECTIONS CRITICAL-ONTOLOGICAL ON INDIVIDUAL AND EDUCATION IN \\ VIEW OF HUMAN EMANCIPATIO
} REFLEXIONES CRÍTICO-ONTOLÓGICA SOBRE EL INDIVIDUO Y LA EDU-
CACIÓN EN LA PERSPECTIVA DE EMANCIPACIÓN HUMANA

\author{
Betânea Moreira de Moraes \\ Professora Doutora do Programa de Pós-graduação em Educação da \\ Universidade Estadual do Ceará (UECE). \\ betaneamoraes@gmail.com \\ Frederico Jorge Ferreira Costa \\ Professor Doutor do Programa de Pós-Graduação em Educação da \\ Universidade Estadual do Ceará (UECE). \\ frederico.costa@uece.br \\ Ruth Maria de Paula Gonçalves \\ Professora Doutora do Programa de Pós-gradução em Educação da \\ Universidade Estadual do Ceará (UECE). \\ ruthm@secrel.com.br
}

\begin{abstract}
RESUMO: O artigo trata de três questões centrais: 1) o que é indivíduo; 2) o que é educação; 3) as relações entre indivíduo e educação. Nesse sentido, buscamos inicialmente trazer para o debate a concepção naturalizada em nossas consciências de que os indivíduos são essencialmente egoístas, competidores, ou seja, que o egoísmo e o ato de competir são inerentes à essência humana - Homo homini lupus -, daí a impossibilidade de superação da exploração do homem pelo homem. No segundo momento, intentamos discutir a atividade essencial da educação e o seu real papel na formação do indivíduo. Por fim, problematizamos a concepção de atividade pedagógica como prática redentora geral, isto é, questionamos a concepção de educação como a verdadeira tábua de salvação, capaz de sanar todas as formas de miséria vigentes em nossos dias. É, pois, no entendimento da contradição que marca a determinação onto-histórica da educação: em seu sentido universal e instituída e historicamente determinada, que apanhamos o lugar e o papel efetivo da educação no processo de constituição do indivíduo livre e de uma vida plena de sentido, qual seja: uma formação assente na luta pela superação da exploração do homem pelo homem.
\end{abstract}

PALAVRAS-CHAVE: Indivíduo. Educação. Ontologia do ser social.

ABSTRACT: The article deals with three central questions: 1) what is individual; 2) What is education; 3) the relationship between the individual and education. In this sense, we seek to initially bring to the debate the naturalized conception in our consciousness that individuals are essentially selfish, competitors, or that selfishness and the act of competing are inherent in human nature - Homo homini lupus - there the impossibility of overcoming the exploitation of man by man. In the second phase, intend to discuss the core business of education and its role in the formation of the individual; finally, we question the design of pedagogical activity as general redemptive practice, that is, question the concept of education as the true lifeline, able to resolve all existing forms of poverty today. It is therefore, according to the contradiction that marks the onto-historical determination of education: in its universal and established and historically determined sense that caught the place and the effective role of education in the free individual constitution process and a full life of meaning, namely, training based on the struggle to overcome the exploitation of man by man.

KEYWORDS: Individual. Education. Ontology marxian.

$\overline{\text { Artigo recebido em maio de } 2015}$

Aprovado em julho de 2015

Cad. Pes., São Luís, v. 22, n. 2, mai./ago. 2015 
RESUMEN: El artículo se ocupa de tres cuestiones centrales: 1) ¿Qué es individuo?; 2) ¿Qué es la educación?; 3) las relaciones entre el individuo y la educación. En este sentido, buscamos, inicialmente, traer para el debate la concepción naturalizada en nuestras conciencias de que los individuos son esencialmente egoístas, competidores, o sea, que el egoísmo y el acto de competir son inherentes a la esencia humana - Homo homini lupus - esta es la concepción de la imposibilidad de superación de la explotación del hombre por el hombre. En el segundo momento, intentamos discutir la actividad esencial de la educación y su real papel en la formación del individuo. Por fin, cuestionamos la concepción de educación como la verdadera línea de salvación, capaz de resolver todas las formas de pobreza existentes en nuestros días. Es, por lo tanto, en el entendimiento de la contradicción que marca la determinación histórica onto-histórica de la educación: en su sentido universal y establecido y históricamente determinada, que cogimos el lugar y el papel efectivo de la educación en el proceso de constitución del individuo libre y de una vida plena de sentido, cual sea: una formación basada en la lucha por la superación de la exploración del hombre por lo hombre.

PALABRAS CLAVE: Individuo. Educación. Ontología del ser social. 
REFLEXÕES | Betânea Moreira de Moraes, Frederico Jorge Ferreira Costa e Ruth Maria de Paula Gonçalves

\section{1 | INTRODUÇÃO}

Este artigo expressa as convergências de estudos realizados em grupos de pesquisas nos quais seus autores estão envolvidos. De fato, é uma exposição sintética dos resultados de um momento de processo de pesquisa que se realiza em rede. A atividade científica enquadra-se nas coordenadas da pesquisa teórico-bibliográfica, por meio da metodologia da leitura imanente, a qual procura compreender as multitudinárias contribuições de Marx para o complexo da educação, por meio da estrutura conceitual de seu pensamento e pela mediação de seus intérpretes.

A análise aqui apresentada gravita em torno de três temáticas básicas: a) conceituação do que é indivíduo; b) delimitação da natureza específica da educação; c) conexões entre indivíduo e complexo da educação.

Tal perspectiva se expressa em três momentos: primeiro, problematizamos a concepção naturalizada em nossas consciências de que os indivíduos são essencialmente egoístas e competidores, ou seja, que o egoísmo e o ato de competir são inerentes à essência humana Homo homini lupus ${ }^{1}$-, tendo como consequência a impossibilidade de superação da exploração do homem pelo homem. Em seguida, discutimos a atividade essencial da educação e o seu real papel na formação do indivíduo. Por fim, refletimos criticamente sobre a concepção de atividade pedagógica como prática redentora geral, questionando a concepção de educação como a verdadeira tábua de salvação, capaz de sanar todas as formas de miséria vigentes em nossos dias.

$\mathrm{Na}$ reflexão sobre o que é o indivíduo, rastreamos sua gênese, bem como tentamos tracejar o processo de humanização do ser social. Abordamos, então, não só o conhecimento do que o indivíduo é, mas também o conhecimento do que ele pode vir-a-ser.

Sobre a educação, buscamos apanhar seu ser em-si enquanto complexo social (a continuidade em meio às contínuas transformações que permite assinalar quais são os elementos que têm um caráter essencial), bem como a função que o referido complexo exerce no processo de humanização do homem (ter como objetivo a possibilidade de desenvolvimento e realização do indivíduo como partícipe do gênero humano).

Para encerrar nosso ensaio, apresentamos alguns elementos que permitem fazer a crítica da vontade educativa entificada na consciência e ação dos educadores, reafirmando a necessidade de recuperação da prática educativa como espaço importante de formação do indivíduo.

\section{2 | EM BUSCA DOS ALICERCES DA INDIVIDUALIDADE HUMANA}

O exercício mais importante dessa análise incide na desconstrução do entendimento de indivíduo como possuidor de uma essência humana dada e imutável. Nesse sentido, é necessário compreender pela raiz que a pessoa não possui uma essência a-histórica, que rege o processo histórico e a vida de cada ser humano (determinada por uma hierarquia presente no cosmos, ou por um ser transcendental) ou, ainda, uma essência natural, biológica que seria desenvolvida ou reprimida (explicada a partir da evolução das espécies - a lei da seleção natural, por exemplo, ou pela tese de Piaget, segundo a qual há uma única lei geral que rege os organismos vivos, do molusco à inteligência humana). Todas essas elaborações teóricas sobre o ser social e sobre o mundo dos homens, as quais atravessam toda a história da filosofia - dos primeiros filósofos à modernidade - têm uma explicação metafísica que desloca o homem à autoria de sua história.

\footnotetext{
${ }^{1}$ Sentença latina criada por Plauto (254-184) em sua obra "Asinaria", um dos mais antigos textos do latim, a qual significa "o homem é o lobo do homem". Tal expressão foi popularizada por Thomas Hobbes, filósofo inglês do século XVIII.
} 
REFLEXÕES | Betânea Moreira de Moraes, Frederico Jorge Ferreira Costa e Ruth Maria de Paula Gonçalves

Marx instaura, no entanto, uma nova relação dos sujeitos com sua história: advoga que são os próprios homens, os autores da história humana. E afirma, então, num acerto de contas com a filosofia de sua época que:

Pode-se distinguir os homens dos animais pela consciência, pela religião e tudo o que se quiser. Os próprios homens começam a se distinguir quando iniciam a produção dos seus meios de vida, passo em frente que é consequência de sua organização corporal. Ao produzirem seus meios de existência os homens indiretamente produzem a sua própria vida material. (MARX; ENGELS, 2005, p. 44-45).

Marx revela assim, que o sujeito se autoproduz pelo trabalho. $O$ trabalho é atividade vital consciente, sensível, eterna e ineliminável na relação do homem com a natureza. Sem trabalho não há sujeito socialmente constituído. Com o trabalho os homens saltam e rompem com o mundo orgânico/animal, se constituindo numa nova forma de ser. O trabalho é, portanto, o momento predominante que inaugura o novo ser, o ser social/humano (LUKÁCS, 2013).

Diferente de todos os animais que encontram as condições de sua existência - sobrevivência e reprodução da espécie -, dadas na natureza e determinadas biologicamente, o homem produz as condições de sua existência através do trabalho, transformando a natureza no mundo humano. Enquanto a essência da atividade vital - o nome já diz "aquela que garante a vida" - do ser orgânico, tanto no reino vegetal quanto no animal, repousa sobre o repor o mesmo da reprodução da vida (semente, goiabeira, goiaba, semente... / abelha, a sua engenharia biológica determina a produção do mel, reprodução da abelha...), é da essência da atividade vital humana a incessante produção do novo. Cada novo objeto produzido traz em si novas necessidades e novas possibilidades. Tomemos como exemplo o momento que o homem conseguiu não mais carregar o fogo, mas produzi-lo, através da fricção de duas pedras ou duas lascas de madeira. Ao descobrir o fogo, surge a necessidade de aperfeiçoar sua produção; com a descoberta da pólvora, cria o fósforo, além do isqueiro, da eletricidade etc.; criam-se novas possibilidades, por exemplo, de alimentação, de proteção contra o frio, de defesa contra os predadores, entre outras.

O trabalho, no entanto, produz não só um novo objeto, mas também um novo homem - o homem é um antes do advento fogo e outro depois. O processo de produção do novo objeto estabelece no sujeito, novos conhecimentos e novas habilidades na esfera do pensar, do fazer, do sentir, dos afetos e dos comportamentos - reside nesse processo o motor da história humana (LUKÁCS, 2013).

Marx e Engels (2005), partindo desse pressuposto real, revelam que a base dinâmico-estruturante do novo tipo de ser - o ser social - é, portanto, o trabalho. No novo objeto tem-se o fundamento do desenvolvimento da sociabilidade, ou seja, das formas de organização social através do desenvolvimento das forças produtivas. No novo homem tem-se o fundamento do desenvolvimento da individualidade, isto é, altera-se o modo de ser do indivíduo, através do desenvolvimento de novas capacidades e habilidades humanas:

Antes de tudo, o trabalho é um processo entre o homem e a Natureza, um processo em que o homem, por sua própria ação, media, regula e controla seu metabolismo com a Natureza. Ele mesmo se defronta com a matéria natural como uma força natural. Ele põe em movimento as forças naturais pertencentes à sua corporalidade, braços e pernas, cabeça e mão, a fim de apropriar-se da matéria natural numa forma útil para sua própria vida. Ao atuar, por meio desse movimento, sobre a Natureza externa a ele e ao modificá-la, ele modifica, ao mesmo tempo, sua própria natureza. Ele desenvolve as potências nela adormecidas e sujeita o jogo de suas forças a seu próprio domínio. (MARX, 1985, p. 149, grifo nosso). 
REFLEXÕES | Betânea Moreira de Moraes, Frederico Jorge Ferreira Costa e Ruth Maria de Paula Gonçalves

Ao modificar a natureza, o indivíduo, em uma via de mão dupla, modifica ao mesmo tempo sua própria natureza. Como temos argumentado, o sujeito não nasce constituído, ou seja, a humanidade não está dada ao homem por força do seu nascimento: o homem aprende a ser e assim, a essência humana é uma essência histórico-social. Pertencer ao gênero/comunidade humana implica por parte de cada exemplar da espécie, isto é, por parte de cada indivíduo, na apropriação das objetivações que constituem o patrimônio do seu gênero, como conhecimentos, habilidades, valores, comportamentos produzidos histórica e coletivamente pelo conjunto de sujeitos. Para humanizar-se, cada criança/indivíduo tem que fazer (interiorizar) seu patrimônio humano.

Trata-se de uma apropriação ativa e não passiva, pois ao apropriar-se do que já existe, cada indivíduo o recria e o renova (não é uma apropriação passiva, fotográfica), configurando, desse modo, sua própria singularidade. Está explicado porque cada pessoa é uma individualidade única/singular.

Para compreendermos o atual momento histórico no qual os indivíduos aparecem como essencialmente egoístas e competitivos, faz-se necessário apreender as formas históricas pelas quais o indivíduo veio a ser o que é. Em outras palavras, faz-se necessário recuperar o processo de autoconstrução do homem, a história de sua humanização, por exemplo, desde a forma comunal primitiva na qual o indivíduo é ser de comunidade/beirando a naturalidade, passando pela antiguidade e pela sociedade feudal, que se encontra na fronteira com a modernidade, chegando ao indivíduo moderno/contemporâneo (esse identificado como essencialmente egoísta e competitivo).

Antes, porém, é necessário demarcar o alicerce sobre o qual se edifica no curso da história o indivíduo e sua humanidade. Chamamos de alicerce porque este caracteriza o ser humano, a essência de seu ser, em qualquer momento histórico, por isso é revelado por Marx como essencial e ineliminável. Esse alicerce é constituído pela tríade: naturalidade, atividade vital consciente e generidade (TEIXEIRA, 1999).

A naturalidade reflete o pressuposto real em que cada exemplar da espécie humana herda uma individualidade biológica com seus atributos e carecimentos; indivíduos que pelo trabalho, intercâmbio ineliminável do sujeito com a natureza e em sociedade, ou seja, só no encontro com outros indivíduos - atividade vital consciente e essencialmente genérica - rompem com os limites naturais de sua existência, desencadeando o processo de individuação e humanização. Assim, as pessoas criam o meio no qual efetivamente vivem; um mundo humano gerido pelo modo de produção, pelas relações de produção que se estabelecem e pela organização social resultante. $\mathrm{Na}$ interatividade com os demais indivíduos, cujo ato originário é a atividade produtiva/o trabalho, a individualidade humana se forma e se efetiva, a partir sempre de sua individualidade biológica e de uma dada forma de sociabilidade.

Se por um lado as referidas categorias (naturalidade, atividade vital consciente e generidade) são determinações essenciais e inelimináveis, por outro têm um caráter dinâmico, pois estão sob o influxo de constantes transformações historicamente determinadas que cria, a cada momento, novas bases para a existência humana, caracterizando assim, o ser social como portador de uma substância histórica potencialmente ilimitada.

\subsection{Formas dinâmicas de individualidade e história dos homens}

A individualidade em seu estágio primitivo, ou seja, na forma comunal de existência, se expressa como afirmação de uma dependência absoluta do indivíduo frente à comunidade: o ser dos indivíduos como mera manifestação ou extensão da comunidade. Temos nesse momento histórico quase a negação pura e simples da individualidade: "Ele [o indivíduo] aparece à origem como ser do gênero (Gattungswesen), tribal, animal de rebanho" (MARX apud ALVES, 1999, p. 48), ou seja, 
beirando a naturalidade. Os indivíduos não têm nome, idade, nacionalidade, entre outros aspectos; nascem, vivem e morrem como dependentes, membros de um conjunto maior. Tal estado se manifesta inicialmente, de maneira totalmente natural na tribo e, depois, nas diferentes formas da comunidade surgida da oposição e da fusão de tribos.

Os indivíduos estão limitados pela comunidade, bem como têm suas potências humanas limitadas por essa mesma relação com o conjunto social. Basta observar que sua atividade produtiva girava em torno da coleta de grãos, da caça e da pesca, de forma que as habilidades e conhecimentos humanos encontravam-se limitados, pelo modo de produzir a existência naquele determinado momento histórico, havendo uma grande dependência das qualidades físicas, como força, velocidade e resistência.

Vale lembrar que a produção do novo, novas necessidades e possibilidades no âmbito da vida material e novos conhecimentos e habilidades na esfera do indivíduo - base dinâmico-estruturante do mundo dos homens - gesta a formação de um sistema de intercâmbio propriamente social que irá dissolver a forma/sistema do rebanho e colocar progressivamente a possibilidade de existências individuais.

Era uma época em que a luta do homem contra a natureza era demasiadamente desigual. $\mathrm{Na}$ luta pela sobrevivência, os homens criam cada vez mais ferramentas, armas e surge, no horizonte da História, a possibilidade da apropriação privada do trabalho alheio. Aumentam, assim, os meios de obtenção dos alimentos ao passo de se produzir mais do que era preciso para o consumo imediato. Com o surgimento do excedente econômico, desenvolveu-se um intercâmbio entre as tribos (MANDEL, 1974).

Com a apropriação do trabalho alheio, instaura-se, então, a propriedade privada dos meios de produção. Os grupos (clãs, tribos) mais fortes, mais produtivos, mais bem armados começaram a dominar os mais fracos. Como resultado, a escravatura foi se estabelecendo e fazendo reformas substanciais na forma de produção da vida, transformando a primitiva sociedade sem classes numa nova forma de organização social, dividida em duas classes: o senhor e o escravo. Nasce a exploração do homem pelo homem sob o modo de produção escravista, o qual impera durante a Idade Antiga.

$\mathrm{Na}$ comunidade antiga clássica, a individualidade ainda aparece como fazendo parte de um todo maior que ultrapassa o indivíduo, permanece a vida em comum como o principal pressuposto da produção e das ações dos homens. No entanto, o elemento comum é a polis/cidade e não o campo. O valor não está no indivíduo Pedro, Paulo, João, mas no cidadão grego ou romano, por exemplo. O que é o indivíduo nesse momento histórico? Uma pessoa que pertence à cidade, à comunidade da polis. Aparece pela primeira vez na história humana a figura estatal, o Estado como a comunidade pública separada da propriedade privada do indivíduo proprietário. As relações superam o patamar dos laços naturais na tribo, dos laços da tradição e passam a ser relações políticas (a etiologia da palavra implica em cidadão, sujeito de direito e deveres) girando em torno da manutenção da polis.

Conforme explicita Alves (1999, p. 65), em sua análise:

A comunidade como Estado, espaço material e formal distinto do mundo privado, aponta para a emergência de uma nova determinação da individualidade, inexistente no modo anterior. Naquele, a propriedade individual era imediatamente propriedade da comunidade, sua extensão ou braço. Na antigüidade clássica, greco-romana, em graus variados, a propriedade privada existe já como posse particularizada do solo onde se assenta a cidade. Assim, surge o indivíduo sob uma dupla figura, proprietário, sujeito privado, e cidadão, sujeito público. 
O momento predominante, no entanto, é e continua sendo, o viver comunal. Portanto, a determinação da pertença comunitária, mesmo em sua forma estatal, não refuta ainda a limitação imanente à individualidade antiga. Trata-se de um sujeito coagido, delimitado, circunscrito por sua existência de membro da cidade, sendo ainda uma forma geral da atividade igualmente limitada à produção, voltada para a subsistência dos seus membros e para a autossuficiência da comunidade.

O dado histórico da antiguidade clássica mais importante para a individualidade é que os homens iniciam o itinerário de dissolução do sistema de rebanho por meio do surgimento de uma contradição entre indivíduo e comunidade. Em outras palavras, "surge o indivíduo sob uma dupla figura, proprietário, sujeito privado, e cidadão, sujeito público” (ALVES, 1999, p. 65), elemento esse constitutivo, para Marx, do processo de individuação humana que caracteriza, portanto, o primeiro momento de efetiva constituição do homem em distinção daqueles modos comunitários mais primitivos.

Da decadência do modo de produção escravista surge o modo de produção feudal vigente na Idade Média, que representa a segunda formação socioeconômica ocidental alicerçada na exploração do homem pelo homem: a classe dos latifundiários nas figuras da nobreza e do clero versus a classe dos servos na pessoa do camponês. Diferente da Idade Antiga, a base das relações passa a ser o campo em oposição à cidade, a ruralização da urbe em conflito à emergência do comércio através do intercâmbio dos burgos. A Idade Média é, portanto, denominada por Marx como forma societária de transição (ALVES, 1999). Embora o modelo da vida seja determinado pelo modo comum agrário do feudo, a diferença marcante em relação à comunidade antiga está no desenvolvimento do trabalho artesanal e urbano ao lado e fora da propriedade fundiária. Essa mudança é determinante para o desenvolvimento do indivíduo: na medida em que muda a relação do trabalhador com os meios de sua atividade, ele passa a ser proprietário das ferramentas de seu trabalho e não mais "ferramentas falantes", um elemento do processo produtivo ao lado do gado ou como apêndice da terra. No entanto, no sistema urbano medieval, as capacidades humanas desenvolvidas estão na esfera das aptidões unilaterais encontram-se limitadas ao exercício de um único ofício sob a lógica da hierarquização das tradições (a relação entre mestre e companheiro, por exemplo).

Assim, tem o indivíduo o conjunto de seu ser delimitado apenas por uma única possibilidade de existência (ferreiro, serralheiro...), não tendo, sequer virtualmente, a possibilidade de desenvolver-se de modo multilateral. O mundo feudal, embora tenha dado passos decisivos no processo de humanização, é também e ainda como Marx (apud ALVES, 1999) indica, uma totalidade limitada e limitante para o desenvolvimento do ser da individualidade ou, talvez, um desenvolvimento ainda limitado e limitante do indivíduo.

Em suma, pode-se afirmar que a determinação própria do indivíduo nessas formas históricas anteriores à modernidade e seu modo de produção capitalista, caracterizam-se tanto pelo precário desenvolvimento das forças produtivas, quanto pelas potências acanhadas e limitadas dos indivíduos. Essa dupla limitação constitui, portanto, o elemento definidor da individualidade ou da sua quase que pura e simples negação (ALVES, 1999).

$\mathrm{O}$ incremento do comércio e das atividades em seu entorno geram novas necessidades e novas possibilidades - artesanato, corporações de ofícios, crescimento da atividade mercantil, acumulação de capital que passou a ser investido na produção, originando, assim, a indústria. Esse processo determina a falência do modo de produção feudal. As relações do tipo comunal/ natural - estratificada, hierarquizada e hereditária - são questionadas, tendo como momento decisivo a Revolução Francesa, cuja bandeira empunhada era a exigência de liberdade, igualdade e fraternidade. Os homens adentram na era moderna, caracterizada por um processo baseado na 
indústria e na cidade. As relações deixam de ser naturais para serem predominantemente sociais. A sociedade deixa de se organizar segundo o direito natural e passa a se organizar através de um direito estabelecido formalmente: o contrato social. Todos os homens são, pela primeira vez na história, livres e iguais, no entanto, os elementos necessários à produção da vida - meios de produção e força de trabalho - pertencem a classes distintas: a capitalista e a trabalhadora. $\mathrm{O}$ trabalhador, então, como proprietário da força de trabalho, vende sua força de trabalho mediante contrato celebrado com o capitalista. Ao adentrar na essência do sistema capitalista, Marx (1985) revela que só formalmente ou no plano da aparência os homens são livres, iguais e proprietários.

$\mathrm{Na}$ realidade, o modo de produção capitalista, assim como no escravismo e no feudalismo, tem por base a exploração do homem pelo homem, não só tem por base, mas é a forma mais incrementada da referida exploração. Os indivíduos aparecem como iguais proprietários de mercadorias (capitalista/proprietário dos meios de produção e trabalhador/proprietário da força de trabalho), portanto, livres para comprar e vender suas mercadorias entre si, regidos apenas por seus interesses particulares. A classe trabalhadora, no entanto, a classe trabalhadora nem efetivamente é proprietária de sua força de trabalho, porque não tem o direito de decidir não vendê-la, nem por que preço vendê-la ao capitalista, sob o imperativo de morrer de fome, por exemplo.

Vivemos, outrossim, sob uma nova forma de servidão: a exploração sem medida do proletariado que convive contraditoriamente com o desenvolvimento sem precedentes das forças produtivas. Tal fenômeno, no plano da individualidade, se expressa na emergência do desenvolvimento das capacidades humanas no patamar mais rico e complexo da história do indivíduo. Isso contraditoriamente conjugado com o imperativo da maioria da comunidade humana, impedida de se apropriar desse patrimônio, tanto material quanto espiritual, visto que a riqueza, embora produzida pelo trabalhador, pertence aos donos dos meios de produção, do capital.

Com a modernidade "assistimos a um só tempo tanto a máxima sociabilidade quanto a emergência da individualidade propriamente dita, nas formas mais plenas e complexas que se tem notícia" (ALVES, 1999, p. 48).

Esse processo, como apontado acima, não se dá sem contradições, pois tem como eixo o divórcio entre indivíduos ativos (os trabalhadores) e as condições de sua atividade (pertence aos proprietários do capital), instaurando uma unidade negativa, na qual as condições de trabalho não somente se tornam independentes, mas de certa maneira se opõem aos indivíduos.

Os indivíduos se encontram livres uns dos outros. O intercâmbio social entre os homens é regido pela lei do valor, da troca de mercadorias equivalentes. A interdependência social se apresenta como simples meio de realizar fins particulares, de forma que a moderna individualidade humana "se caracteriza pelo egoísmo racionalmente exercido" (MARX apud ALVES, 2001, p. 259). Os indivíduos se encontram, dessa maneira, determinados acima de tudo como sujeitos da troca. A lei que regula a troca de mercadorias regula também as relações humanas. Os indivíduos, o que são? Tornam-se meros cambistas e indiferentes, humanamente falando. A diversidade dos conhecimentos e habilidades engendradas pela atividade humana necessária à produção de riqueza perde seu significado, pois a lógica da equivalência como pressuposto do intercâmbio social cancela a diferença entre homens e coisas - tudo se torna mercadoria. Não importa o indivíduo Paulo, Pedro ou João com seus atributos humanos, com sua individualidade singular, ou seja, os homens tornam-se meras personagens econômicas nas figuras do capitalista e trabalhador, de forma que suas individualidades encontram-se reduzidas a meros momentos do processo reprodutivo do capital.

Temos, enfim, com a modernidade, indivíduos cindidos entre a ampliação das potências humanas e o esvaziamento da interatividade marcada pela indiferença, pelo exercício egoísta entre indivíduos, onde impera o "cada um por si e Deus por todos". 
REFLEXÕES | Betânea Moreira de Moraes, Frederico Jorge Ferreira Costa e Ruth Maria de Paula Gonçalves

O capital é definido por Marx (apud ALVES, 1999) como o não-ser do indivíduo, uma vez que a posição da riqueza material coincide com a negação do indivíduo. No entanto, como já argumentado, "[...] é justo e correto afirmar que o mundo do capital, e a individualidade a ele correspondente, aparecem a Marx portando uma tendência civilizatória" (ALVES, 2001, p. 299), tendência essa que pertence somente ao capital, porque inexistente nos modos de produção assentados no pressuposto da naturalidade comunal.

Sob a forma do capital o ser dos indivíduos e a sociabilidade são portadores de uma universalidade virtual, uma vez que a riqueza como capital requer a expansão das potências humanas e, ao mesmo tempo, o aprisionamento de tais potências. Portanto, a libertação das forças produtivas da sua determinação como capital constitui o pressuposto de uma individualidade efetivamente livre e universal.

Em uma sociabilidade alicerçada sobre o trabalho social, "A individualidade não mais seria uma singularidade isolada, alma dos indivíduos contrapostos e indiferentes, postos em contato apenas em virtude da troca de equivalentes" (ALVES, 2001, p. 306). Outrossim, o fazer-se indivíduo implicaria em tomar o outro indivíduo como sua maior riqueza. Os homens passarão a se encontrar para efetivar sua vocação de ser mais, de humanizar-se. Em poucas palavras, a nova sociedade terá por fundamento "a realização social dos indivíduos e não como sua dispersão, egoísmo e separação" (ALVES, 2001, p. 306).

Por fim, em uma nova configuração do ser social, as várias dimensões da vida social se veriam radicalmente alteradas. Sendo o eixo da interação social a cooperação entre indivíduos livremente associados e não a competição, fundada na exploração do homem pelo homem, "[...] certamente tender-se-ia à abolição de comportamentos atravessados e enviesados pelo egoísmo racional" (ALVES, 2001, p. 307). Superados os fundamentos sociais da concorrência, da alienação e, portanto, de individualidades autocentradas e abstratas, o egoísmo racional, que norteia as relações humanas sob o capital, perde sua razão de ser. O indivíduo social emerge em sua plenitude como decorrência de conexões sociais livres e abertas.

\section{3 | DELIMITAÇÃO DA NATUREZA ESPECÍFICA DO COMPLEXO EDUCAÇÃO}

Como argumentamos, o homem não nasce homem; ao contrário dos animais, o homem não nasce "sabendo" o que deve fazer para dar continuidade à sua existência e à da espécie. Ele, então, aprende a ser homem com outros homens que estão de posse do patrimônio humano, ou seja, "das propriedades e aptidões historicamente formadas da espécie humana" (LEONTIEV, 2004, p. 270). Esse processo é, portanto, um processo de educação.

Saviani (1995, p. 17) definiu precisamente a natureza essencial da educação, ao afirmar que ela é "o ato de produzir, direta e intencionalmente, em cada indivíduo singular, a humanidade que é produzida historicamente e coletivamente pelo conjunto dos homens." Nessa definição se destaca o caráter conservador da educação. Segundo Tonet (2005, p. 217-218), o acento conservador reside no fato de que "a maior parte do tempo e das energias no processo educativo é gasto na assimilação [apropriação] dos elementos existentes, sem os quais não se poderia criar o novo e sem os quais o próprio indivíduo não se constituiria [objetivação] como indivíduo." Tal caráter conservador poderá estar dirigido tanto no sentido reacionário/alienador (político-ideológico de manutenção da sociedade de classes/manutenção da alienação) ou revolucionário/emancipador (na perspectiva da transformação social/humanização/emancipação humana).

A educação é, portanto, uma mediação entre o indivíduo e a história humana. É importante destacar que a matéria-prima da ação educativa são indivíduos portadores de consciência e liberdade. Trata-se da ação sobre consciências, portanto, não podemos prever como reagirá o educando. 
REFLEXÕES | Betânea Moreira de Moraes, Frederico Jorge Ferreira Costa e Ruth Maria de Paula Gonçalves

Essa determinação em nada diminui o papel e a importância do educador no processo de formação do educando. A ação sobre a consciência é de suma importância para a formação de uma consciência revolucionária ou reacionária. Daí a importância de levarmos aos nossos alunos o melhor conhecimento sobre a história humana já sistematizada, seja na área das ciências exatas (matemática, biologia, física, química...) ou das ciências humanas (história, geografia...). Sem dúvida, o método tem um peso importante nesse processo, no entanto, assistimos nos últimos anos o deslocamento voltado para as questões do como aprender, tornando secundário o que aprender. A educação escolar tem assumido cada vez mais encargos que extrapolam aquilo que é especificamente pedagógico (família, fome, violência, desemprego, atividades sociais, lazer) e cada vez menos a natureza essencial de sua atividade: transmitir os conhecimentos necessários ao processo de humanização. Mas por que isso acontece?

Ora, a educação, como todas as formas de atividade dos homens, se encontra determinada socialmente. No período da humanidade primitiva, o homem se educava no e pelo trabalho passado às gerações pelo costume, tradição. Com a crescente complexificação do ser social e a divisão da sociedade em classes, ou seja, com o aparecimento de uma classe que não precisa trabalhar para viver, pois ela vive do trabalho alheio, surge uma educação diferenciada, surge a escola - lugar a que tinha acesso a classe ociosa. Por contraposição, a educação geral, da maioria do povo, continua a se dar no próprio processo de trabalho. Até esse momento da história, a educação se realizava através de seu caráter conservador reacionário de reprodução das relações sociais vigentes. A sociedade moderna, contratual, centrada na cidade e na indústria, vai trazer consigo a necessidade e exigência de generalização da escola - exigência de disseminação dos códigos formais, do código da escrita, do domínio dos números, enfim, o acesso à cultura letrada. Desse modo, a forma escolar emerge como forma dominante de educação na sociedade atual (SAVIANI, 1994).

No curso do desenvolvimento da sociedade capitalista ocorreu com a educação escolar um processo contraditório, identificado por Saviani (1994) de hipertrofia versus desvalorização. Em poucas palavras, a exigência da escola se alarga tanto vertical (ela é espichada para baixo/ educação infantil e para cima/pós-graduação) como horizontalmente (a expansão de tempo de permanência nas escolas/tempo integral), isto é o que ele chama hipertrofia da escola que é estendida, mas perde substância, pois se coloca dentro da escola toda uma série de atividades que acabam descaracterizando-a, de forma que tudo é mais importante do que o ato de ensinar, de transmitir o conhecimento acumulado historicamente, conhecimento esse essencial ao processo de formação humana. Essa desvalorização é intencional e essencial para o processo de reprodução das relações sociais capitalistas de dominação. Generaliza-se a educação escolar, mas se saber é poder, é necessário que a instrução para a classe trabalhadora seja dada em doses homeopáticas (SMITH apud SAVIANI, 1994), ou seja, o mínimo de instrução necessária à sua formação como força de trabalho do processo produtivo.

$\mathrm{Na}$ atual forma de organização social capitalista, a educação escolar se generaliza, mas continua a realizar-se predominantemente, sob o caráter conservador reacionário de reprodução das relações sociais vigentes.

\section{4 | INDIVÍDUO E EDUCAÇÃO SOB O SIGNO DA “VONTADE EDUCATIVA”: UMA REFLEXÃO CRÍTICA}

Como analisamos até aqui, é imperioso para a correta colocação da problemática que gravita em torno da relação indivíduo-educação a justa compreensão da determinação social de tais complexos, bem como de suas formas de manifestação. 
REFLEXÕES | Betânea Moreira de Moraes, Frederico Jorge Ferreira Costa e Ruth Maria de Paula Gonçalves

Nesse sentido, ao fazer a crítica à "vontade educativa" (contemporânea e ideologicamente disseminada no seio da educação escolar, assentada na máxima popular de que "querer é poder" - daí radica a crença de que a educação é capaz de redimir, pela mão dos educadores, toda e qualquer mazela social em curso), Alves (2004, p. 5, grifo do autor) explica que:

\begin{abstract}
O educador, como todo indivíduo realmente vivo e ativo, nada tem em comum com a imagem do semideus, existindo de maneira absolutamente livre e, por isso mesmo, absolutamente marginal frente às determinações sociais. É ele, ao contrário, ser social, delimitado pelo modo de ser específico da época social a que pertence, o qual é convocado pelas próprias circunstâncias sociais a agir e levar a efeito a sua atividade. Atividade esta que não é, nem pode ser entendida, como exercício puro da vontade educativa (se me permitirem a analogia com outra força mítica dos nossos dias, a vontade política). Pois, de modo semelhante aos que operam nos parâmetros da vontade política, aqueles que advogam a onipotência da vontade em termos educacionais, tendem a subestimar o ônus efetivo das determinações da realidade social e, imaginando-se imperadores do real, sucumbem miseravelmente ao peso do próprio mundo, convertendo tudo, ora num simples jogo de quem está no poder (política), ora numa questão de método pedagógico (educação).
\end{abstract}

Muito às avessas, a "onipotência da vontade em termos educacionais" tem erigido, outrossim, ainda conforme o autor, o que ele denomina de "incompetência socialmente produzida" (ALVES, 2004, p. 6) que salta da escola, expressa nos fenômenos da evasão, da repetência ou na glorificada e hodierna "solução inclusiva", ancorando-se de pronto na precária formação para o trabalho. Nesse seio, destacamos, ainda, três outras questões levantadas por Alves: o "pressuposto simplista de supor a fonte dos problemas pedagógicos, somente, na 'postura' ou no 'tipo' de educador e de escola (versão autoritária x versão plural da educação)"; seu registro/denúncia do fato de que “a aculturação posta pela vivência escolar é recusada em benefício da 'realidade do aluno' erigida em paradigma" (ALVES, 2004, p. 6, grifo do autor); bem como a necessidade de desvelamento face ao apelo "inovador" de transformar o tempo/espaço da aula em momento lúdico e/ou de administração dos desejos, tensões e motivações dos educandos, advogando, que nada é "mais inepto que abolir as coações imanentes ao estudo e a qualquer tarefa, na esperança de alcançar a 'audiência' ou anuência do 'cliente da sala de aula'” (ALVES, 2004, p. 11, grifo do autor).

Não obstante, é importante sublinhar que a crítica e a impugnação da "vontade educativa" tecidas pelo autor e incorporadas às nossas reflexões, não equivalem ao descarte da atividade pedagógica nem do entendimento da importância e necessária intervenção educativa no processo de tornar-se homem do homem.

Em referência ao seu caráter conservador/emancipatório, no solo da correlação de forças que marca a função social da educação escolar predominantemente voltada à reprodução das relações de dominação, as atividades educativas emancipatórias (TONET, 2005) tornam-se mais que pertinentes e necessárias.

Principalmente nos dias hodiernos, em que decorre da crise estrutural instituída no seio do processo de (re)produção metabólica do capital (MÉSZÁROS, 2000), uma crise do pensamento em geral, que Chasin (1999 apud ALVES, 2004, p. 9) caracteriza por uma tríplice destituição: "a destituição ontológica, a desilusão epistêmica e o descarte do humanismo. Ou seja, a aversão pela objetividade, a descrença na ciência e a destituição do homem." . A destituição ontológica é bem retratada na assertiva de que "não há fatos, só interpretações", a qual reduz o real a uma simples vivência do sujeito. A verdade não corresponderia ao movimento objetivo que estaria além da subjetividade, mas às impressões na consciência do sujeito cognoscente. A desilusão epistêmica revela-se na tentativa de limitação da validade da racionalidade científica, lastreada ontologica- 
mente, àqueles domínios do real que possam ser homogeneizados, formalizados, manipulados, ignorando seu ser objetivamente contraditório e histórico. O descarte do humanismo apresenta-se na negação do homem como produto de sua própria atividade social, de sua história coletiva. A condição humana passa a ser prisioneira de uma ordem natural, sobrenatural ou incognoscível que lhe dá sentido. O mundo dos homens é determinado, em última instância, por algo que está fora da história do gênero humano.

Nesse contexto, é interessante observar, como o faz Alves (2004), que ao final e ao cabo, as posições que se advogam progressistas e libertárias em educação (porque instituídas no seio do movimento de renovação face ao caráter essencialista, conteudista e autoritário da pedagogia tradicional), acabam por reproduzir, reeditar, a tríplice negação humana referida. Nas palavras do autor:

Pois, que outra coisa pode significar uma posição pedagógica em que a formação cultural perde substância, o estímulo à ciência é trocada pelo "livre jogo das opiniões", e o rigor é rebaixado à imposição da opinião do professor, senão que a humanidade atual perdeu seu rumo possível, e com ela a educação?. (ALVES, 2004, p. 9).

Verifica-se assim, que embora a conjunção social se revele um retrato nada libertário, apesar da forma escolar se constituir modo dominante de educação na sociedade atual, cujo caráter social repousa na função de reproduzir predominantemente o socialmente existente, ainda assim a natureza essencial da educação como complexo mediador entre o indivíduo e a história humana jamais poderá ser cancelada, ao fado de se cancelar a própria condição de humanização do homem e de sua existência humana.

O advérbio "predominantemente" revela a importância da atividade educativa no processo de formação das consciências e de transformação social. Por quê? Porque a generalização do acesso à instrução é um processo prenhe de possibilidades. Primeiro, fica difícil fixar limite do quanto de instrução/conhecimento não coloca em risco o controle sobre o saber da classe trabalhadora. Segundo, há o espaço da correlação de forças entre a reivindicação de uma boa escola pelas massas trabalhadoras e o controle da educação pelas camadas dominantes. Terceiro, a relação do ato educativo se dá entre consciências, educador/educando, portanto, o controle nunca pode ser absoluto. Como a educação escolar se alicerça sob tais contradições, os educadores convivem, de um lado, com a impossibilidade de estruturar a educação, no seu conjunto, de modo a estar voltada para a emancipação humana, mas por outro lado, têm a possibilidade de realizar atividades educativas emancipatórias, como já assinalado. Nesse sentido, concordamos com Tonet (2005, p. 214) que afirma: "É melhor fazer pouco na direção certa, do que muito na direção errada." Nessa perspectiva, o filósofo destaca ser necessário:

1) ter clareza quanto ao objetivo final a ser atingido: o fim das relações de exploração do homem pelo homem;

2) compreender bem a lógica que preside a sociedade capitalista;

3) ter clareza acerca da natureza e das funções sociais da educação, de modo a nem subestimá-la nem superestimá-la;

4) ter um domínio tal da área com a qual se trabalha que permita oferecer o melhor conhecimento possível aos educandos;

5) articular as lutas específicas dos educadores com as lutas mais gerais de transformação da ordem social vigente. (TONET, 2005, p. 214). 
Além disso, não se pode deixar de destacar que as amplas massas se educam também no processo histórico da luta de classes. Greves, mobilizações, entre outras formas de atividade, possuem elementos pedagógicos de emancipação social. Por fim, é no entendimento da contradição que marca sua determinação onto-histórica - educação em seu sentido universal e educação escolar instituída e historicamente determinada - que apanhamos o lugar e o papel efetivo da educação no processo de constituição do indivíduo livre e de uma vida plena de sentido, qual seja: uma formação assente na luta pela superação da exploração do homem pelo homem.

\section{5 | CONSIDERAÇÕES FINAIS}

Sem temer a teoria e tomando a práxis como bússola para a formação humana integral, urge a contraposição ao subjetivismo, ao ecletismo teórico e ao irracionalismo constantes nas formulações constituintes da perspectiva educacional hegemônica.

Nesse sentido, é questão primordial articularmos atividades educativas que apontem para o horizonte da emancipação humana, as quais, em conjunto com as lutas empreendidas pelo conjunto dos trabalhadores, sinalizem para o trabalho livre associado e para formação de indivíduos livres e universais.

Portanto, aqui pretendemos enumerar alguns elementos que são resultado de nossa pesquisa teórica, mas que só podem ser averiguados no terreno da luta de classes, isto é, por meio das estratégias rivais pelo controle da sociedade. Isso, porque as contradições postas pela atual crise do capital colocam a possibilidade de consolidação e desenvolvimento de uma estratégia totalizante de reestruturação social que transborde os limites do capital.

Entendemos que qualquer atividade educacional emancipatória pressupõe uma fundamentação teórica do processo de autoconstrução do homem, de sua matriz no trabalho e de suas possibilidades alicerçadas no gênero humano em constante desenvolvimento e na ampliação contínua da esfera da individualidade.

Nesse sentido, as atividades educacionais emancipatórias devem necessariamente ser um momento da alternativa estratégica das forças do trabalho na sua luta contra o capital. Portanto, devem buscar influir no processo reprodutivo-educacional na perspectiva de formar sujeitos conscientes da luta de classes e com acesso crescente às objetivações genéricas possíveis e necessárias para a constituição de individualidades plenas. Para isso, é essencial a produção de objetivações educacionais - didática, programas, currículos, políticas educacionais e teorias -, que sirvam para tornar operativa uma nova forma de reprodução social que supere as relações de produção capitalistas de produção, pois as contradições e problemas da esfera educacional são irredutíveis e insolúveis sem a superação do capitalismo.

Os sujeitos imediatos das atividades educacionais emancipatórias só podem ser os educadores, os educandos e os setores sociais vinculados diretamente à problemática da educação formal, forma prioritária de formação humana no âmbito do capitalismo. É necessária a articulação dessas forças, que sofrem cotidianamente por meio da "educação do capital", mesmo sem ter consciência disso. As atividades educacionais emancipatórias precisam vincular-se e ser expressão dos sujeitos em luta contra as manifestações da crise do capital na esfera educacional. Pois, por mais limitada que seja uma atividade educacional emancipatória, esta é inseparável da atividade organizada dos sujeitos interessados. Na esfera educacional, como nas demais esferas sociais, diante da crise estrutural do capital e seu caráter regressivo para o processo de humanização, qualquer reivindicação, mesmo de cunho democrático, não pode ser atendida satisfatoriamente. 
REFLEXÕES | Betânea Moreira de Moraes, Frederico Jorge Ferreira Costa e Ruth Maria de Paula Gonçalves

Por fim, a constituição de atividades educadoras emancipatórias e o desenvolvimento de individualidades livres e plenas de sentido exigem a mediação com as lutas mais elementares postas na atualidade como: as reivindicações dos educadores em torno do valor de sua força de trabalho; a exigência de democratização do ensino; a pressão por mais verbas para educação; as discussões ao redor dos conteúdos curriculares e práticas pedagógicas; a necessidade de extinção de toda rede privada educacional e estatização de todos os níveis de ensino; a busca pela autonomia integral da educação no nível básico e superior; a luta pela autonomia administrativa e acadêmica; na reivindicação de controle de todo sistema educacional pelos professores, alunos e trabalhadores; a defesa de uma escola única, laica, científica, pública, gratuita, baseada na unidade trabalho intelectual/ trabalho manual e financiada integralmente pelo Estado. 
REFLEXÕES | Betânea Moreira de Moraes, Frederico Jorge Ferreira Costa e Ruth Maria de Paula Gonçalves

\section{Referências}

ALVES, A. J. L. A individualidade moderna nos Grundrisse. 1999. Dissertação (Mestrado em Filosofia) - Universidade Federal de Minas Gerais, Belo Horizonte, 1999.

A individualidade moderna nos Grundrisse. Ensaios Ad Hominem 1: dossiê Marx. São Paulo: Estudos e Edições Ad Hominem, 2001. Tomo V.

A determinação onto-societária do educar ou para uma crítica da vontade educativa. Verinotio: Revista On-line de Educação e Ciências Humanas, ano 1, n. 1, p. 1-12, out. 2004. Disponível em: <http://www.verinotio.org/conteudo/0.53138223991858.pdf>. Acesso em: 17 nov. 2008.

LEONTIEV, A. N. O desenvolvimento do psiquismo. São Paulo: Centauro, 2004.

LUKÁCS, G. Para uma ontologia do ser social II. São Paulo: Boitempo, 2013.

MANDEL, E. Tratado de economia marxista. México, D. F.: Ediciones Era, 1974. Tomo I.
MARX, K. O capital: crítica da economia política. São Paulo: Nova Cultura, 1985. Livro primeiro, tomos I e II.

MARX, K.; ENGELS, F. A ideologia alemã. Tradução Frank Muller. São Paulo: Martin Clared, 2005.

MÉSZÁROS, I. A crise estrutural do capital. Revista Outubro, São Paulo: Instituto de Estudos Socialistas, n. 4, p. 7-15, out. 2000.

SAVIANI, D. O trabalho como princípio educativo frente às novas tecnologias. In: FERRETTI, C. J. et al. (Org.). Novas tecnologias, trabalho e educação: um debate multidisciplinar. Petrópolis: Vozes, 1994.

Pedagogia histórico-crítica: primeiras aproximações. 5. ed. São Paulo: Autores Associados, 1995.

TEIXEIRA, P. T. F. A individualidade humana na obra marxiana de 1843 a 1848. Ensaios Ad Hominem 1: marxismo. São Paulo: Estudos e Edições Ad Hominem, 1999. Tomo I.

TONET, I. Educação, cidadania e emancipação humana. ljuí: Editora Unijuí, 2005. 